Review Article

\title{
Pharmaceutical Pollution: Azole Antifungal Drugs and Resistance of Opportunistic Pathogenic Yeasts in Wastewater and Environmental Water
}

\author{
Mzimkhulu E. Monapathi $\left(\mathbb{D},{ }^{1}\right.$ Joseph C. Oguegbulu $\left(\mathbb{D},{ }^{2}\right.$ Lilian Adogo $\left(\mathbb{D},{ }^{3}\right.$ Michael Klink $(\mathbb{D})$, \\ Bamidele Okoli $\mathbb{D}^{2,4}$ Fanyana Mtunzi $\mathbb{D}^{4},{ }^{4}$ and Johannes S. Modise $\mathbb{D}^{1}$ \\ ${ }^{1}$ Department of Biotechnology and Chemistry, Vaal University of Technology, Andries Potgieter Blvd, Vanderbijlpark 1900, \\ South Africa \\ ${ }^{2}$ Department of Chemical Sciences, Faculty of Science and Technology, Bingham University, PMB 005, Karu, \\ Nasarawa State, Nigeria \\ ${ }^{3}$ Department of Biological Sciences, Faculty of Science and Technology, Bingham University, PMB 005, Karu, \\ Nasarawa State, Nigeria \\ ${ }^{4}$ Institute of Chemical and Biotechnology, Vaal University of Technology, Southern Gauteng Science and Technology Park, \\ Private Bag X021, Vanderbijlpark 1911, South Africa
}

Correspondence should be addressed to Mzimkhulu E. Monapathi; monapathimz@gmail.com

Received 22 March 2021; Revised 8 October 2021; Accepted 15 October 2021; Published 5 November 2021

Academic Editor: Durgesh Jaiswal

Copyright (c) 2021 Mzimkhulu E. Monapathi et al. This is an open access article distributed under the Creative Commons Attribution License, which permits unrestricted use, distribution, and reproduction in any medium, provided the original work is properly cited.

\begin{abstract}
The occurrence of residual antifungal agents through indiscriminate prophylactic use and inappropriate disposal has been reported in wastewater treatment plants (WWTPs), surface water, and groundwater environments. Opportunistic pathogenic aquatic yeasts develop resistance to commonly used antifungal agents through continued exposure to residual antifungal agents in environmental waters. This poses a major public health concern. The present review attempts to provide a brief description of antifungal drugs, with a focus on the most widely used class of antifungal drugs, the azoles, as emerging contaminants in environmental water. Routes of exposure of azole antifungal drugs in wastewater treatment plants, surface water, and groundwater are discussed. The presence of pathogenic yeasts in environmental water, the associated azole resistance, and the risk of exposure to humans and microbiota are highlighted. Management actions needed to curtail the spread and minimise the risks are also indicated. Further research on the occurrence of antifungal agents in wastewater and environmental water is vital to better understand and mitigate the associated health-related risks.
\end{abstract}

\section{Introduction}

Environmental water pollution by pharmaceutical drugs from human activities is a matter of great concern [1]. Goal number six (6) of the United Nations Sustainable Development Goals (SDGs), adopted by the General Assembly in 2015, stipulated that all people would have clean water, sanitation, good health, and wellbeing by 2030 [2]. However, pharmaceutical drugs as emerging contaminants in environmental water pose a threat to the aforementioned SDG target. Increased scientific research has since been directed towards the effects of pharmaceutical drugs on environmental water, flora, biota, and human health, worldwide [3-5]. Residual drugs are frequently detected in environmental matrices and may present potential health risks in different water resources.

Pharmaceutical drugs such as antifungal agents, which are used to prevent or treat human and animal diseases as well as to improve livestock production [6] can reach environmental water bodies through wastewater treatment systems, industrial discharges, aquaculture practices, and agricultural and veterinary runoffs $[7,8]$ (Figure 1). The 


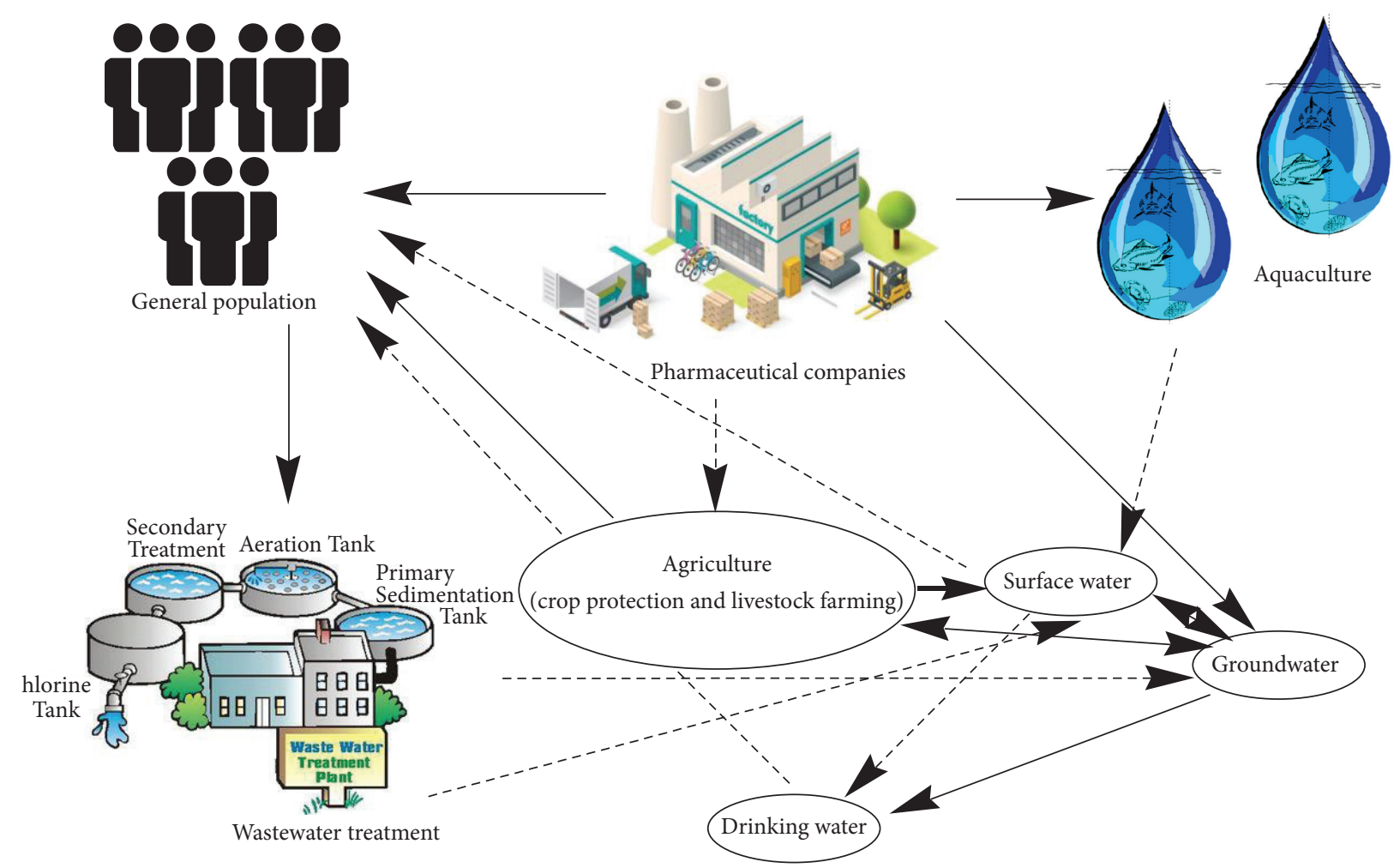

FIGURE 1: Routes of antifungal drugs into environmental water.

recurrence of residual antimicrobial drugs in aquatic environments and drinking water supplies is a public health concern given the potential for aquatic toxicity, development of antimicrobial resistance (AMR) by pathogens, and the overall risk to human life [9].

High concentrations of antimicrobial agents and antimicrobial resistance genes (ARGs) have been observed in WWTPs, groundwater, and surface waters [10]. Conventional wastewater treatment processes are inefficient in tackling the global challenge of removing residual antimicrobial drugs from wastewater and arresting the formation of ARGs in microbes [11]. Therefore, it is vital that wastewater be properly treated before being discharged into the environment to avoid the proliferation of residual antimicrobial drugs and the concomitant antimicrobial resistance.

In the developing world, reports show that the rate of AMR incidence is further amplified by a number of factors; these include poor administration/management of drugs by healthcare professionals and patients as well as poor policies on the part of policymakers [12]. Other contributing factors include sales of poor-quality drugs, inappropriate dispensing (dosage regimen, indication, or contraindications), lack of AMR action plans by regulating bodies, noncompliance with treatment, increased rate of self-medication, and drug overuse by patients, as well as selective pressure of resistant microbial strains over susceptible ones in the animal industry [13].

The current review aims to address the presence of residual antimicrobial agents (especially azole antifungals) and the resulting formation of ARGs by microbes in wastewater treatment plants (WWTPs) and environmental waters (surface and groundwater), as well as the unavoidable development of AMR. The management options to prevent the spread of these contaminants are also discussed. An extensive review was conducted to gather and comprehend current knowledge about potentially pathogenic yeasts and antifungal drugs in wastewater and environmental waters. Research databases including EBSCOhost, Google Scholar, Science Direct, Waters and Oceans Worldwide, and Web of Science were used to find original and peer-reviewed papers. Papers published between 2005 and 2021 have been considered. Literature was filtered using one or more of the keywords: environmental water, wastewater, yeasts, yeast infections, antifungal drugs, and antifungal resistance, as references. Online search was also conducted to consult documents from national and international organizations.

\section{Antifungal Drugs}

Opportunistic pathogenic yeasts (fungi) are known to cause mild to severe infections in humans. Candida and Cryptococcus species are the most significant disease-causing yeasts [14]. The Global Action Fund for Fungal Infections [15] reported high mortality rates for both invasive candidiasis (40\%) and cryptococcal meningitis (10-50\%). Much like with all infectious diseases, immunocompromised people are most vulnerable to yeast infections [16], and this includes people with the human immunodeficiency virus (HIV) and genetic immune deficiencies, as well as cancer and transplant patients. 
Antifungal agents are drugs that selectively destroy infection-causing yeast pathogens within the host without causing significant side effects [17]. However, the indiscriminate use of antifungal agents in managing these infections results conversely in continued growing numbers of yeast infections, and this is due to the development of resistance to these drugs. A look at the classifications of antifungal drugs based on chemical structure and mode of action, as shown in Table 1, is necessary to understand the resistance mechanisms of these pathogens.

Azoles and polyenes are known to form complexes with ergosterol in the plasma membrane, hence altering cell membrane function [23]. Echinocandin antifungal agents inhibit the synthesis of beta-glucan, which is a critical component of pathogenic yeasts' cell wall. Nucleoside analogs interfere with DNA and/or RNA chains, thus terminating the synthesis of nucleic acids [22]. According to Benhamou et al. [24], azoles are the main class of antifungal drugs. They are also shown from systematic research to be the most studied antifungal agents in wastewater and environmental water [25].

Azole drugs are categorized into two distinctive classes: imidazoles (clotrimazole, metronidazole, econazole, ketoconazole, and miconazole) and triazoles (fluconazole, itraconazole, voriconazole, posaconazole, and isavuconazole). In treating yeast infections, they generally inhibit ergosterol biosynthesis by binding to Erg11p, a cytochrome P450 lanosterol $14 \alpha$-demethylase enzyme, which is responsible for the final step of catalysis in ergosterol biosynthesis. In doing so, ergosterol gets depleted from the cell membrane, affecting the plasma membrane and compromising cellular integrity [26]. Furthermore, the inhibition of Erg11p leads to the accumulation of toxic metabolites such as $14 \alpha$-methyl3,6-diol which inhibits yeast growth [26].

Azole antifungals such as clotrimazole, econazole, fluconazole, itraconazole, ketoconazole, miconazole, and metronidazole have been randomly detected from WWTPs and environmental water using advanced Liquid Chromatography-Mass Spectrometry [25, 27-29]. This method successfully determined these pharmaceuticals even at very low concentrations, as shown in Table 2.

Concentrations as low as $0.0009 \mathrm{ng} / \mathrm{L}$ for clotrimazole, $0.0014 \mathrm{ng} / \mathrm{L}$ for ketoconazole, $6.7 \mathrm{ng} / \mathrm{L}$ for miconazole, $10 \mathrm{ng} / \mathrm{L}$ for itraconazole, $20.1 \mathrm{ng} / \mathrm{L}$ for econazole, $35.6 \mathrm{ng} / \mathrm{L}$ for metronidazole, and $56.2 \mathrm{ng} / \mathrm{L}$ for fluconazole have been reported [32]. On the upper limit, contrary to a report from the WHO information sheet [46], which stated that not more than $100 \mathrm{ng} / \mathrm{L}$ of pharmaceutical drugs have been detected from surface, ground, and partly treated water, this review shows detected concentrations above $100 \mathrm{ng} / \mathrm{L}$ for some antifungal agents, with levels up to $13,200 \mathrm{ng} / \mathrm{L}$ for fluconazole reported by Velpandian et al. [29]. The abundance of fluconazole, in particular, can be explained by the fact that its underlying safety makes it the most extensively used antifungal agent [47]. Furthermore, its relatively high aqueous mobility results in higher concentrations in environmental waters where other azole drugs, due to their hydrophobic nature, tend to adsorb to solid surfaces [31]. Evaluation of the environmental threat of residual pharmaceutical drugs indicates that certain azole drugs (climbazole, clotrimazole, and fluconazole) have a potential for mutagenicity towards the endocrine system of fish [48] and, hence, could be detrimental to aquatic life. In summary, antifungal drugs in wastewater and environmental water are a significant emerging class of environmental pollutants.

2.1. Antifungal Drug Resistance. Resistance is characterised by the persistence and progression of infection under appropriate antimicrobial agent therapy. Hence, management of opportunistic microbial infections has been markedly limited by antimicrobial resistance (AMR) [49], which results from prophylactic use in human medicine or from continuous misuse of antimicrobial agents in other sectors of commercial activity [50]. With continued exposure to residual antimicrobials, pathogenic microbes are able to develop and carry multiple antimicrobial resistance genes (ARGs) encoding resistance to various classes of antibiotics such as tetracycline, quinolone, aminoglycoside, and $\beta$-lactam antimicrobials [51-53]. In a study on livestock-associated water sources in the United States, McMillan et al. [54] reported that all tested isolates contained at least one ARG, while many tested microbial plasmids were found to contain more than one ARG. These studies establish that a diverse group of ARG-carrying plasmids developed by these microbes proliferate the development of AMR in general.

Mechanistically, opportunistic pathogenic yeasts acquire resistance to antifungal agents by developing antimicrobial resistance genes (ARGs), which may be propagated by vertical or horizontal gene transfer [55]. Many pathogenic yeasts isolated from environmental water have shown resistance to multiple frequently used clinical azoles such as econazole, fluconazole, itraconazole, ketoconazole, metronidazole, and miconazole. ARGs such as Candida drug resistance genes (CDR1 and $C D R 2)$, multidrug resistance genes (MDR1), and fluconazole resistance genes (FLU1) have been detected in C. albicans isolates from clinical and wastewater environments [56]. Furthermore, an effluxpump-mediated resistance mechanism observed in clinical settings has also been shown in aquatic yeasts [57].

Resistance in pathogenic yeasts is a pressing public health threat given that it significantly limits and/or prolongs therapeutic and treatment options leading to higher healthcare costs and sometimes death [56]. According to the UN Ad hoc Interagency Coordinating Group on Antimicrobial Resistance Report [57], if nothing is done, up to 10 million lives will be lost to diseases associated with drug resistance each year by 2050 . Additionally, up to 24 million people will experience utmost poverty due to antimicrobial resistance by 2030 [58].

\section{Incidence and Consequences of Antifungal Drugs in Wastewater and Environmental Waters}

Antifungal agents are used in prophylaxis to prevent opportunistic fungal infections in humans or curatively to treat 
TABLE 1: Classes of antifungal drugs, their modes of action, and target cells in pathogenic yeasts.

\begin{tabular}{|c|c|c|c|c|}
\hline Antifungal agents & $\begin{array}{l}\text { Specific } \\
\text { examples }\end{array}$ & Mode of action & Target cells & References \\
\hline Azoles & $\begin{array}{c}\text { Clotrimazole } \\
\text { Ketoconazole } \\
\text { Miconazole }\end{array}$ & $\begin{array}{l}\text { Inhibit the activity of cytochrome P450-dependent } 14-\alpha \text {-sterol } \\
\text { demethylase }\end{array}$ & $\begin{array}{l}\text { Cell } \\
\text { membrane }\end{array}$ & {$[18-20]$} \\
\hline Polyenes & $\begin{array}{c}\text { Nystatin } \\
\text { Amphotericin B } \\
\text { Natamycin }\end{array}$ & $\begin{array}{l}\text { Inhibit the activity of cytochrome P450-dependent } 14-\alpha \text {-sterol } \\
\text { demethylase }\end{array}$ & $\begin{array}{l}\text { Cell } \\
\text { membrane }\end{array}$ & {$[17,20,21]$} \\
\hline Echinocandins & $\begin{array}{l}\text { Caprofungin } \\
\text { Micafungin } \\
\text { Anidulafungin }\end{array}$ & Inhibit the synthesis of $\beta$-D-glucan synthase & Cell wall & {$[18,20]$} \\
\hline $\begin{array}{l}\text { Nucleoside } \\
\text { analogs }\end{array}$ & Flucytosine & Interfere with DNA and RNA synthesis & Nucleus & {$[20,22]$} \\
\hline
\end{tabular}

TABLE 2: Levels of azole antifungal agents detected in WWTPs and environmental water.

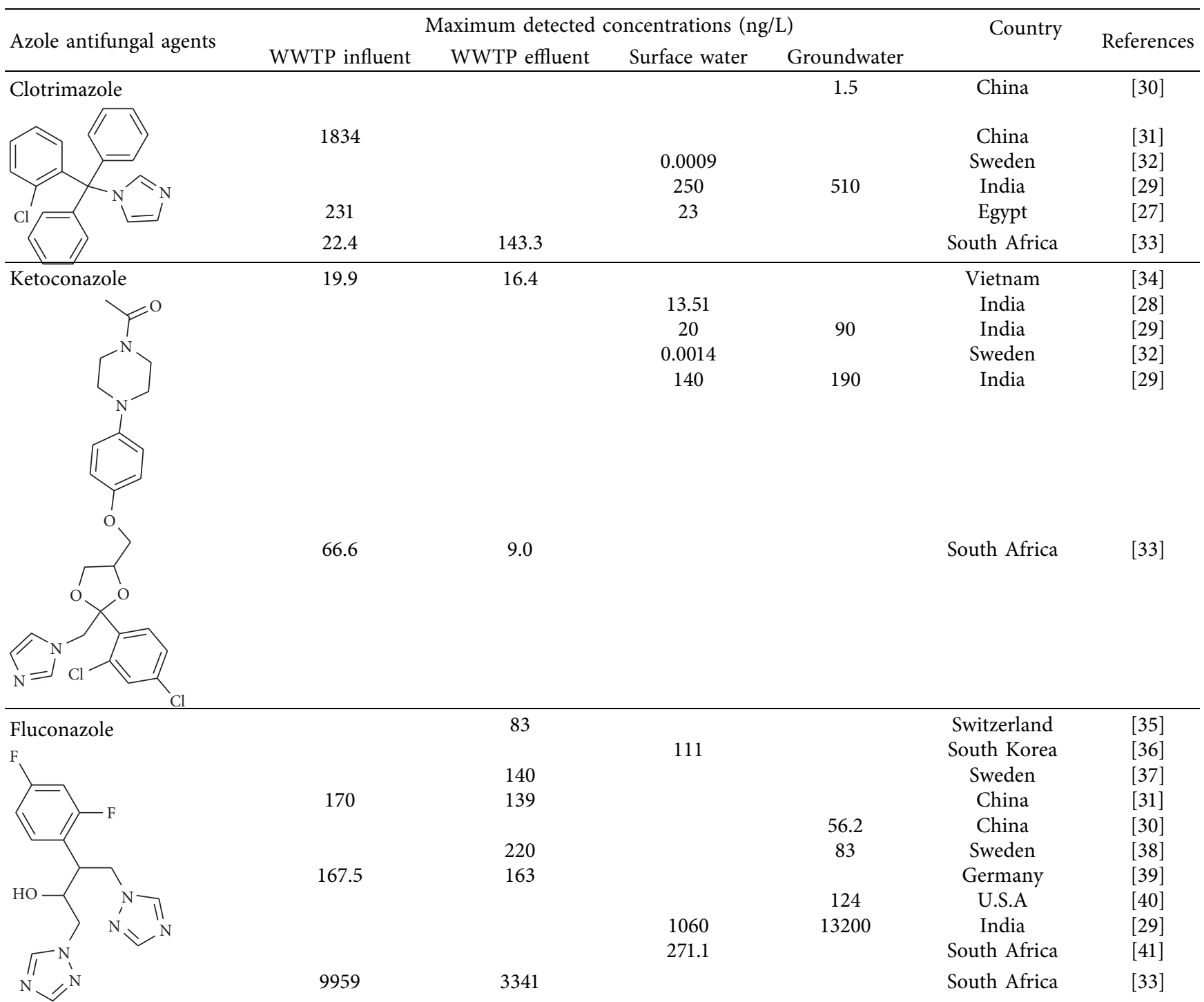


TABle 2: Continued.

\begin{tabular}{|c|c|c|c|c|c|c|}
\hline \multirow{2}{*}{ Azole antifungal agents } & \multicolumn{4}{|c|}{ Maximum detected concentrations (ng/L) } & \multirow[t]{2}{*}{ Country } & \multirow{2}{*}{ References } \\
\hline & WWTP influent & WWTP effluent & Surface water & Groundwater & & \\
\hline Itraconazole & & & 20 & 10 & India & {$[29]$} \\
\hline & & 23.7 & & & South Africa & {$[33]$} \\
\hline Econazole & 86 & & & & China & {$[31]$} \\
\hline & & 20.1 & & & South Africa & {$[33]$} \\
\hline Miconazole & 6.3 & & & & China & {$[42]$} \\
\hline $\mathrm{Cl}$ & 1086 & & & & China & {$[31]$} \\
\hline & & & & 6.7 & China & {$[30]$} \\
\hline & 65.6 & 17.8 & & & India & {$[43]$} \\
\hline & 180 & 25 & & & India & {$[44]$} \\
\hline & & & 1450 & 78 & India & [29] \\
\hline & & & 13.51 & & India & {$[28]$} \\
\hline & 16.7 & 16.4 & & & South Africa & {$[33]$} \\
\hline Metronidazole & 145 & 158 & & & Portugal & {$[45]$} \\
\hline $\mathrm{OH}$ & & & & 35.6 & Taiwan & {$[35]$} \\
\hline & 19.9 & 16.4 & & & Vietnam & [35] \\
\hline$\rangle$ & & & 13.51 & & India & {$[28]$} \\
\hline$\rangle$ & & & 20 & 90 & India & [29] \\
\hline
\end{tabular}


the same. The proliferation of these drugs comes about due to ease of over-the-counter access [56], often leading to residual antifungal agents in water sources down the line. Contaminated recreational waters, for example, are natural reservoirs of resistant microorganisms [60]. Hence, direct human contact with resistant microbes in such waters through recreational activities puts the population at risk, hampering individual abilities to fight microbial infections [61]. Furthermore, WWTPs and environmental matrices constitute indirect routes of human exposure to residual antifungal agents and resistant microbes.

\subsection{Wastewater Treatment Plants. WWTPs are a major} reservoir of residual pharmaceutical drugs, including antifungal agents, because influents to WWTPs are generally contaminated with pharmaceutical pollutants and heavy metals among other things. Although the level of the ubiquity of antifungal drugs, in particular, as well as the associated role of WWTPs, has not been fully elucidated [25], it is apparent that antimicrobial residues in WWTPs mainly result from the uncontrolled disposal of unused medicines into sewage systems as well as incompletely metabolised antimicrobial drugs passed through urine excretion [62]. Secondly, other WWTP influents from ARGloaded environments, such as hospitals and agricultural sites, contribute significant ARG load from pathogenic microorganisms [63]. Hence, WWTPs are a significant meeting point for opportunistic pathogenic yeasts and residual antifungal agents.

Much of the reviewed work in the present study shows higher concentrations of antifungals at WWTP influents than in their effluents as expected (Table 2) [25, 31, 34, $39,42-44]$. However, the presence of residual antifungals in the effluents suggests that WWTPs only partially remove/ degrade these drugs, and in some cases, the resulting metabolites retain antimicrobial activity.

Furthermore, various reports have shown that conventional WWTP processes do not efficiently disinfect the effluents in order to inactivate the microbes $[64,65]$. Hence, WWTP effluents retain a high ARG load. It is suggested that the existence of microorganisms in floc and biofilm forms in WWTPs explain why they are hotspots for ARGs transfer $[66,67]$. Other factors such as reactor design, temperature, and the chemical properties of the wastewater (i.e., chemical oxygen demand (COD), suspended solids (SSs), and dissolved oxygen) are also touted to affect the outcome of the treatment process and the fate of the ARGs [68-72].

Although AMR and ARGs in WWTPs are well studied in general $[55,73,74]$, little has been done on antifungal resistance genes, in particular [25]. Yeasts species, some of which are opportunistic pathogens, have been studied in WWTPs $[25,33,75]$, and reports establish that, with continued exposure to residual antifungal drugs, they develop resistance via ARG development and transfer. The inadequacy of the treatment processes and the sustained high levels of AMR in microorganisms from WWTP effluents suggest that WWTPs are a major source of AMG contamination to the environment. However, the multiplicity of factors at play in a WWTP design make it difficult to speak to the level of influence the wastewater treatment process has on the dynamics of ARG transfer and on the ultimate development of AMR within and outside the system. This continues to be an evolving research interest and calls for targeted management strategies and further public health attention toward WWTP designs.

On the freshwater front, WWTPs serve among other things for water reclamation (i.e., wastewater treatment and reuse) and reclaimed water is considered an alternative to scarce freshwater resources [76]. The burden of residual antimicrobial drugs and the potential development of ARGs in them pose a global water safety and quality challenge. Regulatory wastewater quality guidelines and standards are generally based on chemical indices. Microbial indices, including pathogenic yeasts, are generally not incorporated in wastewater regulatory frameworks. Thus, the microbial safety profile in engineered drinking water systems cannot be determined under the current framework.

\subsection{Environmental Waters}

3.2.1. Surface Water. Pharmaceutical pollution of environmental water is poorly regulated; thus, there is an increasing number of pharmaceutical residues in freshwater environments [6]. Wastewater effluents containing antimicrobial agents, antimicrobial resistance-carrying microbes, and ARGs may be discharged into surface water systems from WWTPs, sewer lines, or septic systems carrying human excreta, urine, and domestic wastewater [77]. Human activities such as aquaculture, livestock farming, crop infection control, and crop production also release pharmaceutical drug residues into receiving freshwater environments [78]. Table 2 shows some of the azole antifungal agents measured from surface water. High azole levels have been recorded for fluconazole $(1060 \mathrm{ng} / \mathrm{L})$ and miconazole $(1450 \mathrm{ng} / \mathrm{L})$ with lower levels for clotrimazole $(0.0009 \mathrm{ng} / \mathrm{L})$ and ketoconazole $(0.0014 \mathrm{ng} / \mathrm{L})$ in Swedish river basins [32]. Lower concentrations of azole drugs were detected in surface water than in WWTP effluents. This is explained by dilution in surface water and adhesion to rock sediments, as well as bioaccumulation in aquatic organisms [48]. The occurrence of antifungal drugs in surface water results in human health-related problems and adversely affects aquatic organisms.

Furthermore, opportunistic pathogenic yeasts have been isolated from surface water environments [79] with resistance observed towards most clinically used antifungal agents, given prolonged contact with residual pharmaceutical drugs [80]. Infection from these pathogenic yeasts may come easily through contact with or ingestion of contaminated surface water [81]. Hence, surface water, as a possible breeding ground for opportunistic pathogenic antifungal resistant yeasts, presents a public health risk to people who directly use these waters.

3.2.2. Groundwater. Antifungal agents from surface water may be transferred to the groundwater through a lateral or vertical hydraulic hyporheic exchange [82]. Unused 
antimicrobials from domestic waste as well as veterinary antimicrobial drugs in livestock excreta get dumped in landfills and end up in soil and groundwater [83]. Seepage from landfills into underground water is especially prevalent in regions with no regulation on the dumping of unused medicines [84]. Some reports on levels of antifungal agents detected in groundwater environments are shown in Table 2. High azole concentrations (fluconazole $(13000 \mathrm{ng} / \mathrm{L})$ ) [29] and lower levels for clotrimazole $(1.5 \mathrm{ng} / \mathrm{L})$, ketoconazole $(3.3 \mathrm{ng} / \mathrm{L})$, and miconazole $(6.7 \mathrm{ng} / \mathrm{L})$ have been reported [30].

Diverse yeast genera that include pathogenic species have also been isolated from groundwater resources $[75,85,86]$. Constant exposure of these pathogenic yeasts to residual antifungal drugs in groundwater would result in further acquired antifungal resistance. As shown in Figure 1, groundwater could serve as a direct route for the spread of pathogenic antifungal resistant yeasts and other ARG-carrying microbes to humans. Groundwater systems are the primary sources of drinking water; thus, the potential use of contaminated groundwater is an obvious and crucial health risk.

\section{Required Management Actions}

The current observed high rate of antimicrobial resistance is not commensurate with the limited number of clinically available antifungal treatment options. Thus, antifungal resistance is a threat to the clinical management of fungal infections [87]. The unreasonable use of antifungal agents in both clinical and agriculture settings requires urgent action in order to mitigate future disaster.

The establishment of antimicrobial stewardship programs is the first step in a string of management actions needed to manage the spread of antifungal resistance and AMR in general. The functions of the programme would include conducting research and surveillance, overseeing treatment guidelines and infection control, advising on the implementation of legal regulations, and promoting education on antimicrobial use and resistance [88].

Efforts to intensify surveillance and monitoring of antimicrobial use and resistance must be made, especially in developing countries where this is an ongoing challenge due to lack of capacity [89]. Regulations on the manufacture, supply, and administration of antimicrobial agents should be strengthened and better adhered to. Suitable measures should be put in place to guide on the appropriate use of antimicrobial agents in agriculture and livestock production [90]. Healthcare facilities must be managed such that hospital effluents are disinfected before release to the environment [91]. Proper training on industrial and medical wastewater management, sanitation, vaccination coverage, and personal hygiene should be given to stakeholders [55], and educational programs for both medical and nonmedical personnel should be encouraged.

As established, conventional treatment plants do not effectively remove residual antifungal agents and resistance determinants [64], and there are currently hardly any legal regulations or guidelines on permissible levels for discharge of antimicrobial agents from WWTPs into the environment
[55]. Even agricultural and farming sites may be contaminated when dewatered sludge from treatment plants are used as fertilizer. The persistence of antifungal agents throughout their environmental life cycle confirms these inadequacies in traditional wastewater treatment strategies [35]. New technologies must, therefore, be developed, and existing treatment options should be improved upon [55].

\section{Conclusions}

Water pollution is a global concern. Chemical and microbial elements constitute a large portion of pollution to water. Wastewater and WWTPs are recognised as significant points in the spread of antifungal resistance in the environment. Continued prolonged exposure of pathogenic yeasts to antifungal agents results in antifungal resistance in yeasts which renders treatment of yeast infections by commonly used antifungal drugs less effective and tending to ineffective. Due to current ineffective water treatment processes, antifungal agents, antifungal resistance genes, and antifungal resistant yeasts also end up in drinking water resources. Unregulated disposal and discharge of antifungal agents into environmental waters pose potential human health risks from exposure to water resources. To minimise the spread of AMR, strict regulations and policies on management, use, and disposal of antifungal agents should be implemented and better adhered to.

The present study reviewed the work carried out on residual antifungal drugs from WWTP, surface water, and groundwater environments. Low to high concentrations have been observed. Fluconazole is the highest occurring antifungal drug in wastewater treatment plants, surface water, and groundwater environments. Limited comprehensive and systematic research has been conducted on the occurrence and associated health risks of azole antifungal drugs in water resources. Similarly, there are limited studies focused on antifungal resistance genes compared to numerous aquatic studies on antibiotic resistance genes in WWTPs and environmental water. The present review highlights this paucity of data and prompts for more detection studies to be directed towards antifungal resistant genes in order to help to establish clear interactions and concrete relationships among antifungal agents, pathogenic yeasts, antifungal resistance genes, and antifungal resistance in aquatic environments.

\section{Data Availability}

The data used to support the findings of this study are included within the article.

\section{Disclosure}

The views expressed are those of the authors and not of any agency.

\section{Conflicts of Interest}

The authors declare no conflicts of interest. 


\section{Acknowledgments}

The authors would like to thank the Department of Chemistry at Vaal University of Technology for providing the necessary support and facilities to accomplish this work.

\section{References}

[1] A. Courtier, A. Cadiere, and B. Roig, "Human pharmaceuticals: why and how to reduce their presence in the environment," Current Opinion in Green and Sustainable Chemistry, vol. 15, pp. 77-82, 2019.

[2] G. Schwan, "Sustainable development Goals: a call for global partnership and cooperation," GAIA-Ecological Perspectives for Science and Society, vol. 28, no. 2, p. 73, 2019.

[3] M. Kumar, K. Dhangar, A. K. Thakur et al., "Antidrug resistance in the Indian ambient waters of Ahmedabad during the COVID-19 pandemic," Journal of Hazardous Materials, vol. 416, 2021.

[4] T. H. Miller, N. R. Bury, S. F. Owen, J. I. MacRae, and L. P. Barron, "A review of the pharmaceutical exposome in aquatic fauna," Environmental Pollution, vol. 239, pp. 129-146, 2018.

[5] V. Srivastava, B. Vaish, A. Singh, and R. P. Singh, "Nutrient recovery from municipal waste stream: status and prospects," Urban Ecology, Elsevier, Amsterdam, Netherlands, pp. 265297, 2020.

[6] S. A. Kraemer, A. Ramachandran, and G. G. Perron, "Antibiotic pollution in the environment: from microbial ecology to public policy," Microorganisms, vol. 7, no. 6, p. 180, 2019.

[7] I. Alderton, B. R. Palmer, J. A. Heinemann et al., "The role of emerging organic contaminants in the development of antimicrobial resistance," Emerging Contaminants, vol. 7, pp. 160-171, 2021.

[8] D. D. T. T. D. Senarathna, K. H. D. N. Abeysooriya, T. Vithushana, and D. M. N. A. Dissanayake, "Veterinary pharmaceuticals in aquaculture wastewater as emerging contaminant substances in aquatic environment and potential treatment methods," MOJ Ecology and Environmental Sciences, vol. 6, no. 3, pp. 98-102, 2021.

[9] J. L. Tambosi, L. Y. Yamanaka, H. J. José, R. De Fátima Peralta Muniz Moreira, and H. F. Schröder, "Recent research data on the removal of pharmaceuticals from sewage treatment plants (STP)," Quimica Nova, vol. 33, pp. 411-420, 2010.

[10] E. Felis, J. Kalka, A. Sochacki et al., "Antimicrobial pharmaceuticals in the aquatic environment - occurrence and environmental implications," European Journal of Pharmacology, vol. 866, Article ID 172813, 2020.

[11] C. X. Hiller, U. Hübner, S. Fajnorova, T. Schwartz, and J. E. Drewes, "Antibiotic microbial resistance (AMR) removal efficiencies by conventional and advanced wastewater treatment processes: a review," The Science of the Total Environment, vol. 685, pp. 596-608, 2019.

[12] J. A. Ayukekbong, M. Ntemgwa, and A. N. Atabe, "The threat of antimicrobial resistance in developing countries: causes and control strategies," Antimicrobial Resistance and Infection Control, vol. 6, no. 1, p. 47, 2017.

[13] I. A. Rather, B. C. Kim, V. K. Bajpai, and Y. H. Park, "Selfmedication and antibiotic resistance: crisis, current challenges, and prevention," Saudi Journal of Biological Sciences, vol. 24, no. 4, pp. 808-812, 2017.
[14] D. Z. P. Friedman and I. S. Schwartz, "Emerging fungal infections: new patients, new patterns, and new pathogens," Journal of Fungi, vol. 5, no. 3, p. 67, 2019.

[15] Global Action Fund for Fungal Infections, "Fungal disease frequency," 2020, https://gaffi.org/why/fungal\%20diseasefrequency/.

[16] C. Y. Low and C. Rotstein, "Emerging fungal infections in immunocompromised patients," F1000 Medicine Reports, vol. 3, p. 14, 2011.

[17] S. Seyedmousavi, H. Rafati, M. Ilkit, A. Tolooe, MT. Hedayati, and P. Verweij, "Systemic antifungal agents: current status and projected future developments," in Methods in Molecular Biology, pp. 107-139, Humana Press Inc., Totowa, NJ, USA, 2017.

[18] S. Nami, A. Aghebati-Maleki, H. Morovati, and L. AghebatiMaleki, "Current antifungal drugs and immunotherapeutic approaches as promising strategies to treatment of fungal diseases," Biomedicine \& Pharmacotherapy, vol. 110, pp. 857-868, 2019.

[19] J. E. Nett and D. R. Andes, "Antifungal agents," Infectious Disease Clinics of North America, vol. 30, no. 1, pp. 51-83, 2016.

[20] K. Pianalto and J. Alspaugh, "New horizons in antifungal therapy," Journal of Fungi, vol. 2, no. 4, p. 26, 2016.

[21] F. Ciesielski, D. C. Griffin, J. Loraine, M. Rittig, J. DelvesBroughton, and B. B. Bonev, "Recognition of membrane sterols by polyene antifungals amphotericin B and natamycin, a 13C MAS NMR study," Frontiers in Cell and Developmental Biology, vol. 4, p. 57, 2016.

[22] L. Eyer, R. Nencka, E. de Clercq, K. Seley-Radtke, and D. Růžek, "Nucleoside analogs as a rich source of antiviral agents active against arthropod-borne flaviviruses," Antiviral Chemistry and Chemotherapy, vol. 26, Article ID 204020661876129, 2018.

[23] T. Di Mambro, I. Guerriero, L. Aurisicchio, M. Magnani, and E. Marra, "The yin and yang of current antifungal therapeutic strategies: how can we harness our natural defenses?" Frontiers in Pharmacology, vol. 10, p. 80, 2019.

[24] R. I. Benhamou, M. Bibi, K. B. Steinbuch et al., "Real-time imaging of the azole class of antifungal drugs in live Candida cells," ACS Chemical Biology, vol. 12, no. 7, pp. 1769-1777, 2017.

[25] H. A. Assress, R. Selvarajan, H. Nyoni, H. J. O. Ogola, B. B. Mamba, and T. A. M. Msagati, "Azole antifungal resistance in fungal isolates from wastewater treatment plant effluents," Environmental Science and Pollution Research, vol. 28, no. 3, pp. 3217-3229, 2021.

[26] A. A. Sagatova, M. V. Keniya, R. K. Wilson, B. C. Monk, and J. D. A. Tyndall, "Structural insights into binding of the antifungal drug fluconazole to Saccharomyces cerevisiae lanosterol 14 $\alpha$-demethylase," Antimicrobial Agents and Chemotherapy, vol. 59, no. 8, pp. 4982-4989, 2015.

[27] M. Abou-Elwafa Abdallah, K.-H. Nguyen, A. J. Ebele, N. N. Atia, H. R. H. Ali, and S. Harrad, "A single run, rapid polarity switching method for determination of 30 pharmaceuticals and personal care products in waste water using Q-Exactive Orbitrap high resolution accurate mass spectrometry," Journal of Chromatography A, vol. 1588, pp. 68-76, 2019.

[28] A. Hossain, S. Nakamichi, M. Habibullah-Al-Mamun, K. Tani, S. Masunaga, and H. Matsuda, "Occurrence and ecological risk of pharmaceuticals in river surface water of Bangladesh," Environmental Research, vol. 165, pp. 258-266, 2018. 
[29] T. Velpandian, N. Halder, M. Nath et al., "Un-segregated waste disposal: an alarming threat of antimicrobials in surface and ground water sources in Delhi," Environmental Science \& Pollution Research, vol. 25, pp. 29518-29528, 2018.

[30] X. Peng, W. Ou, C. Wang et al., "Occurrence and ecological potential of pharmaceuticals and personal care products in groundwater and reservoirs in the vicinity of municipal landfills in China," The Science of the Total Environment, vol. 490, pp. 889-898, 2014.

[31] X. Peng, Q. Huang, K. Zhang, Y. Yu, Z. Wang, and C. Wang, "Distribution, behavior and fate of azole antifungals during mechanical, biological, and chemical treatments in sewage treatment plants in China," The Science of the Total Environment, vol. 426, pp. 311-317, 2012.

[32] C. Lindim, J. van Gils, D. Georgieva, O. Mekenyan, and I. T. Cousins, "Evaluation of human pharmaceutical emissions and concentrations in Swedish river basins," The Science of the Total Environment, vol. 572, pp. 508-519, 2016.

[33] H. A. Assress, R. Selvarajan, H. Nyoni, K. Ntushelo, B. B. Mamba, and T. A. M. Msagati, "Diversity, co-occurrence and implications of fungal communities in wastewater treatment plants," Scientific Reports, vol. 9, no. 1, 2019.

[34] Y.-C. Lin, W. W.-P. Lai, H.-h. Tung, and A. Y.-C. Lin, "Occurrence of pharmaceuticals, hormones, and perfluorinated compounds in groundwater in Taiwan," Environmental Monitoring and Assessment, vol. 187, no. 5, 2015.

[35] M. Kahle, I. J. Buerge, A. Hauser, M. D. Müller, and T. Poiger, "Azole fungicides: occurrence and fate in wastewater and surface waters," Environmental Science \& Technology, vol. 42, no. 19, pp. 7193-7200, 2008.

[36] J.-W. Kim, H.-S. Jang, J.-G. Kim et al., "Occurrence of pharmaceutical and personal care products (PPCPs) in surface water from mankyung river, South Korea," Journal of Health Science, vol. 55, no. 2, pp. 249-258, 2009.

[37] R. H. Lindberg, J. Fick, and M. Tysklind, "Screening of antimycotics in Swedish sewage treatment plants-waters and sludge," Water Research, vol. 44, no. 2, pp. 649-657, 2010.

[38] J. Fick, RH. Lindberg, J. Fång, J. Magnér, L. Kaj, and E. Brorström-Lundén, "Screening 2014: analysis of pharmaceuticals and hormones in samples from WWTPs and receiving waters," 2015.

[39] R. Gurke, J. Rossmann, S. Schubert et al., "Development of a SPE-HPLC-MS/MS method for the determination of most prescribed pharmaceuticals and related metabolites in urban sewage samples," Journal of Chromatography B, vol. 990, pp. 23-30, 2015.

[40] S. M. Elliott, M. L. Erickson, A. L. Krall, and B. A. Adams, "Concentrations of pharmaceuticals and other micropollutants in groundwater downgradient from large on-site wastewater discharges," PLoS One, vol. 13, no. 11, Article ID e0206004, 2018.

[41] M. Monapathi, S. Horn, T. Vogt et al., “Antifungal agents, yeast abundance and diversity in surface water: potential risks to water users," Chemosphere, vol. 274, Article ID 129718, 2021.

[42] Q. Huang, K. Zhang, Z. Wang, C. Wang, and X. Peng, "Enantiomeric determination of azole antifungals in wastewater and sludge by liquid chromatography-tandem mass spectrometry," Analytical and Bioanalytical Chemistry, vol. 403, no. 6, pp. 1751-1760, 2012.

[43] B. Subedi, K. Balakrishna, R. K. Sinha, and N. Yamashita, "Mass loading and removal of pharmaceuticals and personal care products, including psychoactive and illicit drugs and artificial sweeteners, in five sewage treatment plants in India,"
Journal of Environmental Chemical Engineering, vol. 3, pp. 2882-2891, 2015.

[44] B. Subedi, K. Balakrishna, D. I. Joshua, and K. Kannan, "Mass loading and removal of pharmaceuticals and personal care products including psychoactives, antihypertensives, and antibiotics in two sewage treatment plants in southern India," Chemosphere, vol. 167, pp. 429-437, 2017.

[45] L. H. M. L. M. Santos, M. Gros, S. Rodriguez-Mozaz et al., "Contribution of hospital effluents to the load of pharmaceuticals in urban wastewaters: identification of ecologically relevant pharmaceuticals," The Science of the Total Environment, vol. 461-462, pp. 302-316, 2013.

[46] World Health Organisation (WHO), Information Sheet: Pharmaceuticals in Drinking-Water, World Health Organization, Geneva, Switzerland, 2016, https://www.who.int/ publications/m/item/information-sheet-pharmaceuticals-indrinking-water.

[47] S. Teng Chai, A. Haydar Ali Tajuddin, N. A. Wahab, N. Mustafa, N. Sukor, and N. A. Kamaruddin, "Fluconazole as a safe and effective alternative to ketoconazole in controlling hypercortisolism of recurrent cushing's disease: a case report," International Journal of Endocrinology and Metabolism, vol. 16, no. 3, 2018.

[48] Z.-F. Chen and G.-G. Ying, "Occurrence, fate and ecological risk of five typical azole fungicides as therapeutic and personal care products in the environment: a review," Environment International, vol. 84, pp. 142-153, 2015.

[49] A. A. Denegre, M. L. Ndeffo Mbah, K. Myers, and N. H. Fefferman, "Emergence of antibiotic resistance in immunocompromised host populations: a case study of emerging antibiotic resistant tuberculosis in AIDS patients," PLoS One, vol. 14, no. 2, Article ID e0212969, 2019.

[50] E. Y. Klein, T. P. Van Boeckel, E. M. Martinez et al., "Global increase and geographic convergence in antibiotic consumption between 2000 and 2015," Proceedings of the $\mathrm{Na}$ tional Academy of Sciences, vol. 115, no. 15, pp. E3463-E3470, 2018.

[51] L. M. Glenn, R. L. Lindsey, J. F. Frank et al., "Analysis of antimicrobial resistance genes detected in multidrug-ResistantSalmonella entericaSerovar typhimurium isolated from food animals," Microbial Drug Resistance, vol. 17, no. 3, pp. 407-418, 2011.

[52] P. Jain, S. Sudhanthirakodi, G. Chowdhury et al., "Antimicrobial resistance, plasmid, virulence, multilocus sequence typing and pulsed-field gel electrophoresis profiles of Salmonella enterica serovar Typhimurium clinical and environmental isolates from India," PLoS One, vol. 13, no. 12, Article ID e0207954, 2018.

[53] T. J. Johnson, J. L. Thorsness, C. P. Anderson et al., "Horizontal gene transfer of a colV plasmid has resulted in a dominant avian clonal type of salmonella enterica serovar Kentucky," PLoS ONE, vol. 5, no. 12, Article ID e15524, 2010.

[54] E. A. McMillan, S. K. Gupta, L. E. Williams et al., "Antimicrobial resistance genes, cassettes, and plasmids present in salmonella enterica associated with United States food animals," Frontiers in Microbiology, vol. 10, pp. 832-918, 2019.

[55] M. Pazda, J. Kumirska, P. Stepnowski, and E. Mulkiewicz, "Antibiotic resistance genes identified in wastewater treatment plant systems-a review," The Science of the Total Environment, vol. 697, Article ID 134023, 2019.

[56] R. H. Jensen, "Resistance in human pathogenic yeasts and filamentous fungi: prevalence, underlying molecular mechanisms and link to the use of antifungals in humans and the 
environment," Danish Medical Journal, vol. 63, no. 10, Article ID B5288, 2016.

[57] M. E. Monapathi, C. C. Bezuidenhout, and O. H. J. Rhode, "Efflux pumps genes of clinical origin are related to those from fluconazole-resistant Candida albicans isolates from environmental water," Water Science and Technology, vol. 77, no. 4, pp. 899-908, 2018.

[58] Ad Hoc Interagency Coordination Group on Antimicrobial Resistance, 2019, No Time to Wait: Securing the Future from Drug-Resistant Infections, IACG Discussion Paper, https:// www.who.int/publications/i/item/no-time-to-wait-securingthe-future-from-drug-resistant-infections.

[59] R. Rameshkumar and N. Arunagirinathan, "Drug-Resistant Bacterial Infections in HIV Patients," in Advances in HIV and AIDS Control, IntechOpen, London, UK, 2018.

[60] S. P. Nappier, K. Liguori, A. M. Ichida, J. R. Stewart, and K. R. Jones, "Antibiotic resistance in recreational waters: state of the science," International Journal of Environmental Research and Public Health, vol. 17, no. 21, p. 8034, 2020.

[61] A. C. Singer, H. Shaw, V. Rhodes, and A. Hart, "Review of antimicrobial resistance in the environment and its relevance to environmental regulators," Frontiers in Microbiology, vol. 7, p. 1728, 2016.

[62] K. Kümmerer and M. Hempel, "Green and sustainable pharmacy," 2010.

[63] H. Sanderson, C. Fricker, R. S. Brown, A. Majury, and S. N. Liss, "Antibiotic resistance genes as an emerging environmental contaminant," Environmental Reviews, vol. 24, no. 2, pp. 205-218, 2016.

[64] F. Barancheshme and M. Munir, "Strategies to combat antibiotic resistance in the wastewater treatment plants," Frontiers in Microbiology, vol. 8, p. 2603, 2018.

[65] H. Sanderson, R. Stephen Brown, P. Hania, T. A. McAllister, A. Majury, and S. N. Liss, "Antimicrobial resistant genes and organisms as environmental contaminants of emerging concern: addressing global public health risks," in Management of Emerging Public Health Issues and Risks: Multidisciplinary Approaches to the Changing Environment, V. T. Benoit Roig and K. Weiss, Eds., Academic Press, Cambridge, MA, USA, pp. 147-187, 2018.

[66] J. M. Cerrato, J. O. Falkinham, A. M. Dietrich, W. R. Knocke, C. W. McKinney, and A. Pruden, "Manganese-oxidizing and -reducing microorganisms isolated from biofilms in chlorinated drinking water systems," Water Research, vol. 44, no. 13, pp. 3935-3945, 2010.

[67] M. Sustarsic, "Wastewater treatment: understanding the activated sludge process," 2009, http://www.d.umn.edu/\% 7Erdavis/courses/che4601/articles/Activated\%20Sludge.pdf.

[68] J. Chen and M. Zhang, "The Par3/Par6/aPKC complex and epithelial cell polarity," Experimental Cell Research, vol. 319, no. 10, pp. 1357-1364, 2013.

[69] J. Du, P. Li, H. Liu, D. Lü, H. Liang, and Y. Dou, "Phenotypic and molecular characterization of multidrug resistant klebsiella pneumoniae isolated from a university teaching hospital, China," PLoS One, vol. 9, no. 4, 2014.

[70] C. W. McKinney, R. S. Dungan, A. Moore, and A. B. Leytem, "Occurrence and abundance of antibiotic resistance genes in agricultural soil receiving dairy manure," FEMS Microbiology Ecology, vol. 94, no. 3, 2018.

[71] C. W. McKinney, K. A. Loftin, M. T. Meyer, J. G. Davis, and A. Pruden, "Tet and sul antibiotic resistance genes in livestock lagoons of various operation type, configuration, and antibiotic occurrence," Environmental Science \& Technology, vol. 44, no. 16, pp. 6102-6109, 2010.
[72] A. Novo and C. M. Manaia, "Factors influencing antibiotic resistance burden in municipal wastewater treatment plants," Applied Microbiology and Biotechnology, vol. 87, no. 3, pp. 1157-1166, 2010.

[73] J. Alexander, N. Hembach, and T. Schwartz, "Evaluation of antibiotic resistance dissemination by wastewater treatment plant effluents with different catchment areas in Germany," Scientific Reports, vol. 10, no. 1, p. 8952, 2020.

[74] M. Pazda, M. Rybicka, S. Stolte et al., "Identification of selected antibiotic resistance genes in two different wastewater treatment plant systems in Poland: a preliminary study," Molecules, vol. 25, no. 12, p. 2851, 2020.

[75] M. E. Monapathi, C. C. Bezuidenhout, and O. H. James Rhode, "Aquatic yeasts: diversity, characteristics and potential health implications," Journal of Water and Health, vol. 18, no. 2, pp. 91-105, 2020.

[76] R. Wang, M. Ji, H. Zhai, Y. Guo, and Y. Liu, "Occurrence of antibiotics and antibiotic resistance genes in WWTP effluentreceiving water bodies and reclaimed wastewater treatment plants," The Science of the Total Environment, vol. 796, 2021.

[77] United Nations, "Wastewater management a UN-water analytical brief analytical Brief," 2014.

[78] Organisation for Economic Co-operation and Development (OECD), "Pharmaceutical residues in freshwater: hazards and policy responses," 2019, https://www.oecd.org/environment/ resources/Pharmaceuticals-residues-in-freshwater-policyhighlights-preliminary-version.pdf.

[79] D. Libkind, P. Buzzini, B. Turchetti, and C. A. Rosa, "Yeasts in continental and seawater," in Yeasts in Natural Ecosystems: Diversity, pp. 1-61, Springer International Publishing, Berlin, Germany, 2017.

[80] A. C. M. Milanezi, J. P. D. Witusk, and S. T. van der Sand, "Antifungal susceptibility of yeasts isolated from anthropogenic watershed," Anais da Academia Brasileira de Ciências, vol. 91, no. 1, Article ID 20170369, 2019.

[81] A. O. Medeiros, L. M. Kohler, J. S. Hamdan, B. S. Missagia, F. A. R. Barbosa, and C. A. Rosa, "Diversity and antifungal susceptibility of yeasts from tropical freshwater environments in Southeastern Brazil," Water Research, vol. 42, no. 14, pp. 3921-3929, 2008.

[82] J. Lewandowski, A. Putschew, D. Schwesig, C. Neumann, and M. Radke, "Fate of organic micropollutants in the hyporheic zone of a eutrophic lowland stream: results of a preliminary field study," The Science of the Total Environment, vol. 409, no. 10, pp. 1824-1835, 2011.

[83] Q. Sui, X. Cao, S. Lu, W. Zhao, Z. Qiu, and G. Yu, "Occurrence, sources and fate of pharmaceuticals and personal care products in the groundwater: a review," Emerging Contaminants, vol. 1, no. 1, pp. 14-24, 2015.

[84] M. Bashaar, V. Thawani, M. A. Hassali, and F. Saleem, "Disposal practices of unused and expired pharmaceuticals among general public in Kabul," BMC Public Health, vol. 17, no. 1, p. 45, 2017.

[85] M. G. Arroyo, O. P. Frota, J. T. M. Peresi et al., "Wide diversity of fungal species found in wellwater for human consumption: an analytical cross-sectional study," Sao Paulo Medical Journal, vol. 137, no. 6, pp. 512-516, 2019.

[86] M. N. Novak Babič, P. Zalar, B. Ženko, S. Džeroski, and N. Gunde-Cimerman, "Yeasts and yeast-like fungi in tap water and groundwater, and their transmission to household appliances," Fungal Ecology, vol. 20, pp. 30-39, 2016.

[87] V. Pai, A. Ganavalli, and N. Kikkeri, "Antifungal resistance in dermatology," Indian Journal of Dermatology, vol. 63, no. 5, pp. 361-368, 2018. 
[88] C. Sharma, N. Rokana, M. Chandra et al., "Antimicrobial resistance: its surveillance, impact, and alternative management strategies in dairy animals," Frontiers in Veterinary Science, vol. 4, 2018.

[89] World Health Organisation (WHO), Antimicrobial Resistance, World Health Organization, Geneva, Switzerland, 2020, https://www.who.int/news-room/fact-sheets/detail/ antimicrobial-resistance.

[90] V. S. Brauer, C. P. Rezende, A. M. Pessoni et al., "Antifungal agents in agriculture: friends and foes of public health," Biomolecules, vol. 9, no. 10, 2019.

[91] World Health Organisation, J. Emmanuel, U. Pieper et al., Safe Management of Wastes from Healthcare Activities, World Health Organization, Geneva, Switzerland, 2014, http://apps. who.int/iris/bitstream/10665/85349/1/9789241548564_eng. pdf. 